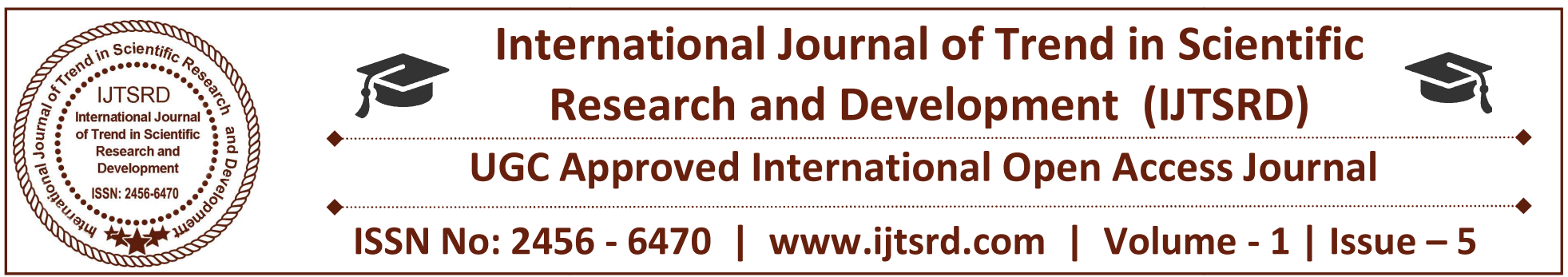

\title{
Customer Service Evaluation Applied to Pedagogy Degree
}

\author{
López Lazcano Judith $\mathbf{N}$. \\ Universidad Insurgentes, Mexico
}

\author{
Jaimes Pérez Josué Iván \\ Instituto Tecnológico de Milpa \\ Alta, Mexico
}

\author{
Vega Torres Gisela \\ Instituto Tecnológico de Cuautla, \\ México
}

\section{ABSTRACT}

The objective of the present study is to evaluate the customer service applied to the pedagogy degree in its night shift. To carry out this research, a population study was applied and a representative sample was calculated using a $95 \%$ confidence level and a $5 \%$ error allowed. The Servqual instrument was used to achieve the stated objective. The results of the investigation showed that the lowest dimensions were the security with $66.43 \%$ and the reliability $68.71 \%$.

Keywords - Customer service, evaluation and pedagogy degree

\section{INTRODUCTION}

The development of logistic organizations and competition in this sector has allowed the evolution of logistics services beyond the fulfilment of delivery times. At present, there is a need to offer differentiated services with respect to competitors and also to substitute services that daily seek to displace traditional logistic services (Pecina, 2014).

Continuing with the ideas of the same author (2014), he mentions that it is therefore important that logistics organizations identify the quality elements in the services they provide and measure them with the levels of satisfaction they are generating in their clients, to stay and grow In these increasingly competitive and excellent markets as the Mexican market begins, more in volume and importance than in the development of logistics companies.

Grönroos (1982) mentions that, in general, service quality has been identified as complex, diffuse and abstract in nature (Zeithaml, 1988; Carman, 1990) and Parasuraman, Zeithmal and Berry (1985) Which the client realizes about the superiority or overall excellence of the product, is an attitude, although not equivalent, to satisfaction and is described as the degree and direction of discrepancies between customer perceptions and expectations. Both the quality and the services are of paramount importance for the consumers nowadays, besides being essential for the success of a company. In this way, both should be united in a competitive strategy of cooperation with the client, seeking the total satisfaction of the client (Botero and Peña, 2006).

Fisher and Navarro (1994) define a service as: A type of economic good, it constitutes what it calls the tertiary sector, everyone who works and does not produce goods is supposed to produce services.

Developed in 1988, SERVQUAL (Service Quality) is an instrument that seeks to measure service quality. This tool is developed based on the need to establish strategies based on quality by the companies and institutions of the sector, all this as a prerequisite for its success (Parasurman 1988).

The construction of the additive scale used by Parasuraman et al. (1988) was carried out under the methodology proposed by Churchill et al. (1979). In this context, Parasuraman et al. (1985) were able to define the existence of ten potential dimensions, which grouped a total of ninety-seven service quality measurement items. After refinement of this preliminary scale, they obtained an instrument composed of twenty-two attributes grouped in five dimensions, which explain the quality of the service 
in the industries of this sector. These five dimensions are defined below, according to the findings of Parasuraman et al. (1988).

$>$ Tangibles: Physical facilities, equipment and appearance of staff.

Reliability: Ability of service to perform as promised reliably and accurately.

Responsiveness: Willingness to help clients and provide them with an appropriate service.

Safety: Knowledge and courtesy of employees and their ability to inspire confidence.

Empathy: Care and personalized attention that the service company gives to its clients.

\section{GENERAL OBJECTIVE}

Evaluate the customer service in the students of the degree of pedagogy in the area of coordination in their night shift.

\section{SPECIFIC OBJECTIVES}

$>$ Identify the areas of opportunity that the pedagogical coordination area has regarding student service.

Evaluate the customer service in the students of the pedagogy degree in their night shift of the coordination area.

$>$ Propose improvement alternatives for the service to students in the area of coordination.

\section{JUSTIFICATION}

Customer service is a key differentiator in marketing, thanks to it can be positioned in the minds of potential customers and generate a competitive advantage. Satisfaction and customer value generation are two factors that influence the customer both before and after receiving the service (Blanco, 2009).
The development of this work will also serve as a reference guide for all schools that wish to measure the service they provide to students.

\section{METHODOLOGY}

The study population will be the students of pedagogy of the shift. Table 1 shows the distribution of men and women who make up this study area.

\section{Table 1: Example of Study Population}

\begin{tabular}{|c|c|}
\hline Gender & Total \\
\hline Female & 94 \\
\hline Male & 42 \\
\hline
\end{tabular}

In the table above it can be observed that there are more women who study the degree of pedagogy.

Once the study population was known, the representative sample of the study was calculated. A $95 \%$ confidence interval and a maximum permissible error of $5 \%$ were used for the investigation. The formula used was the one proposed by Dr. Bolaños (2012), which is used for finite or known populations. The formula is as follows:

$n=\left[\frac{Z_{\alpha}^{2} N^{*} p * q}{i^{2}(N-1)+Z_{\alpha}^{2} * p^{*} q}\right]$

Where:

$\mathrm{N}$ : sample size

$\mathrm{N}$ : population size

$Z$ : value corresponding to the gauss distribution, for the investigation $Z=95 \%$, which is equal to 1.96 .

P: expected prevalence of the parameter to be evaluated, if not known $(\mathrm{p}=0.5)$, which makes the sample size larger.

Q: 1 - $p$ (if $p=70 \%, q=30 \%$ )

I: error expected to be committed if it is $5 \%, i=0.05$

The development of the formula is as follows:

$$
n=\left[\frac{(1.96)^{2} * 136 * 0.5 * 0.5}{(0.05)^{2}(136-1)+(1.96)_{6}^{2} * 0.5 * 0.5}\right]=\frac{130.6144}{0.3375+0.9604}=\frac{130.6144}{1.2979}=100.63 \approx 101
$$


The study noted that of a population of 136 students with which the University counts, using 95\% reliability and $5 \%$ error allowed, will require 101 teachers for research.

\section{ANALYSIS OF RESULTS}

At this stage the results obtained will be described, once the surveys have been carried out to the representative sample of the study.

Figure 1 represents the results of the dimension: Tangible elements.

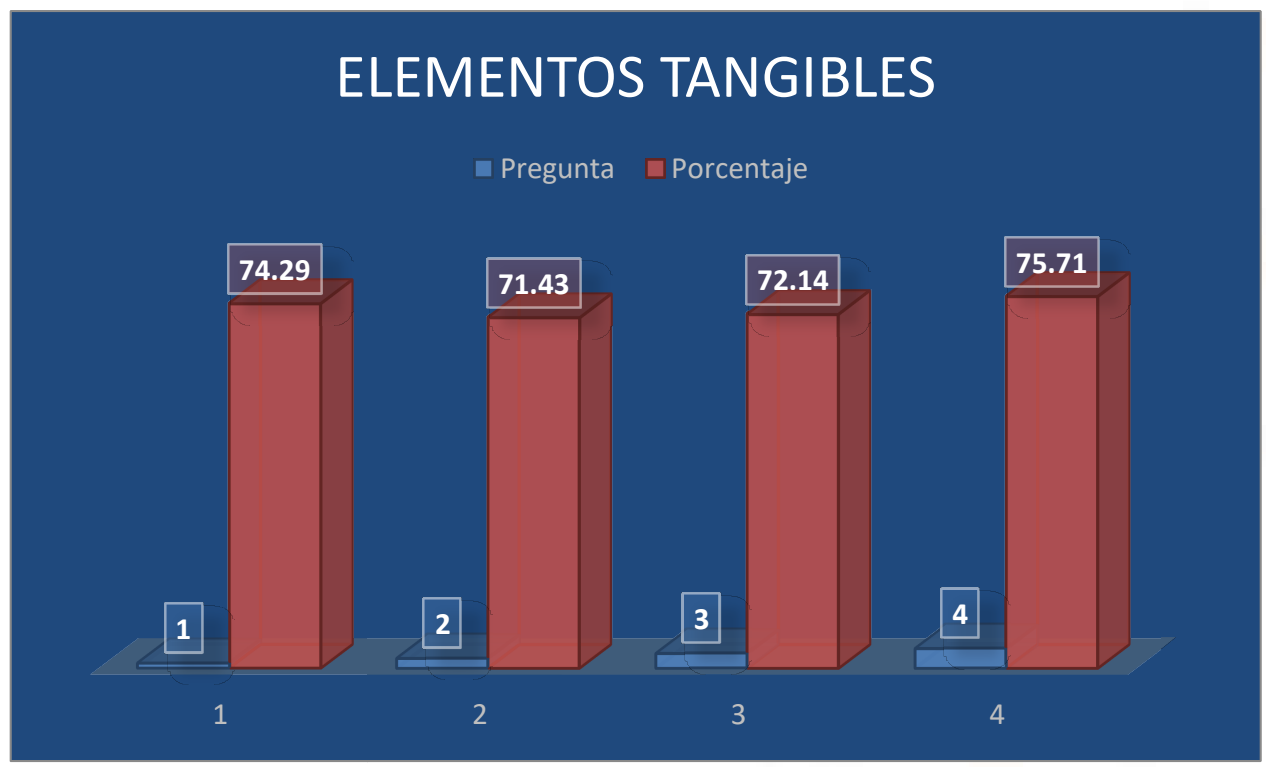

Figure 1: Example of results of tangible elements.

The previous figure shows that all the results of the questions that make up the dimension of Tangible Elements have results in average of $70 \%$, which represents a regular result.

Figure 2 represents the results of the dimension: Reliability.

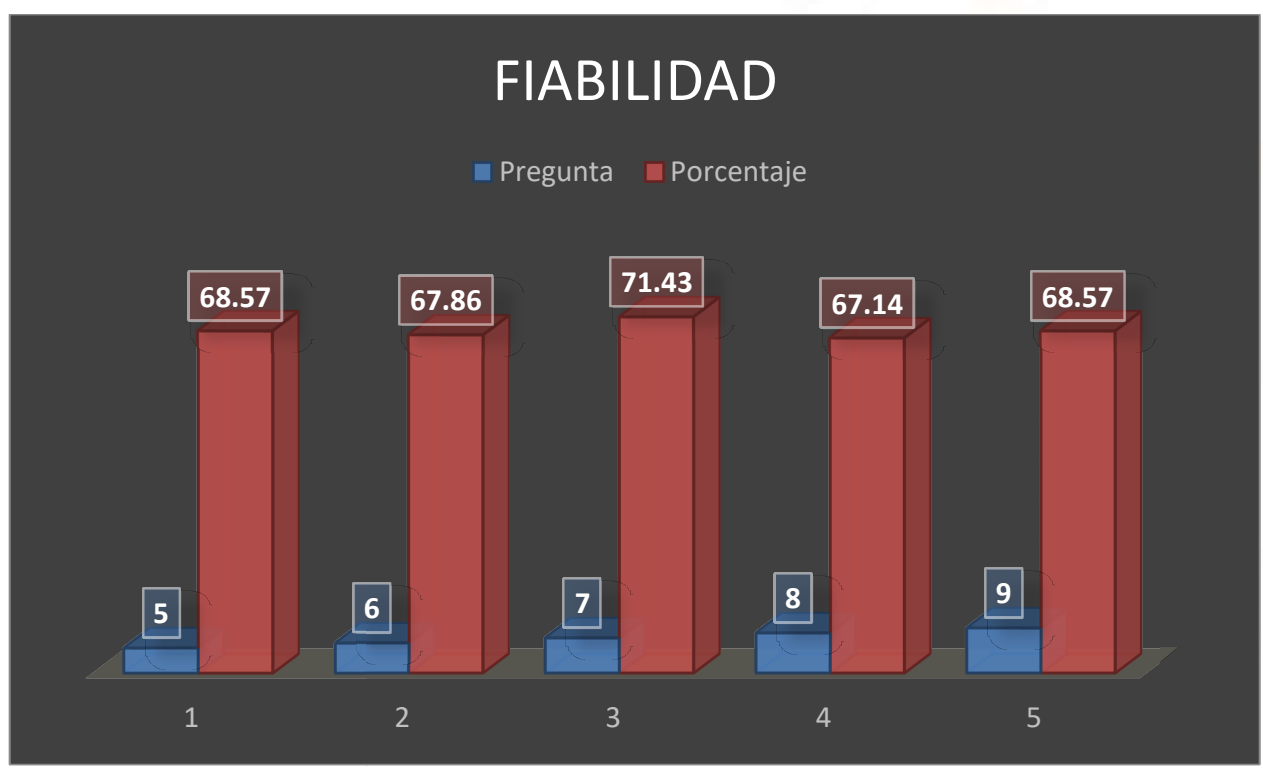

Figure 2: Example of results of reliability elements

The previous figure shows that all the results of the questions that make up the Reliability dimension have results on average of $68 \%$, which represents a regular result. 
Figure 3 represents the results of the dimension: Empathy.

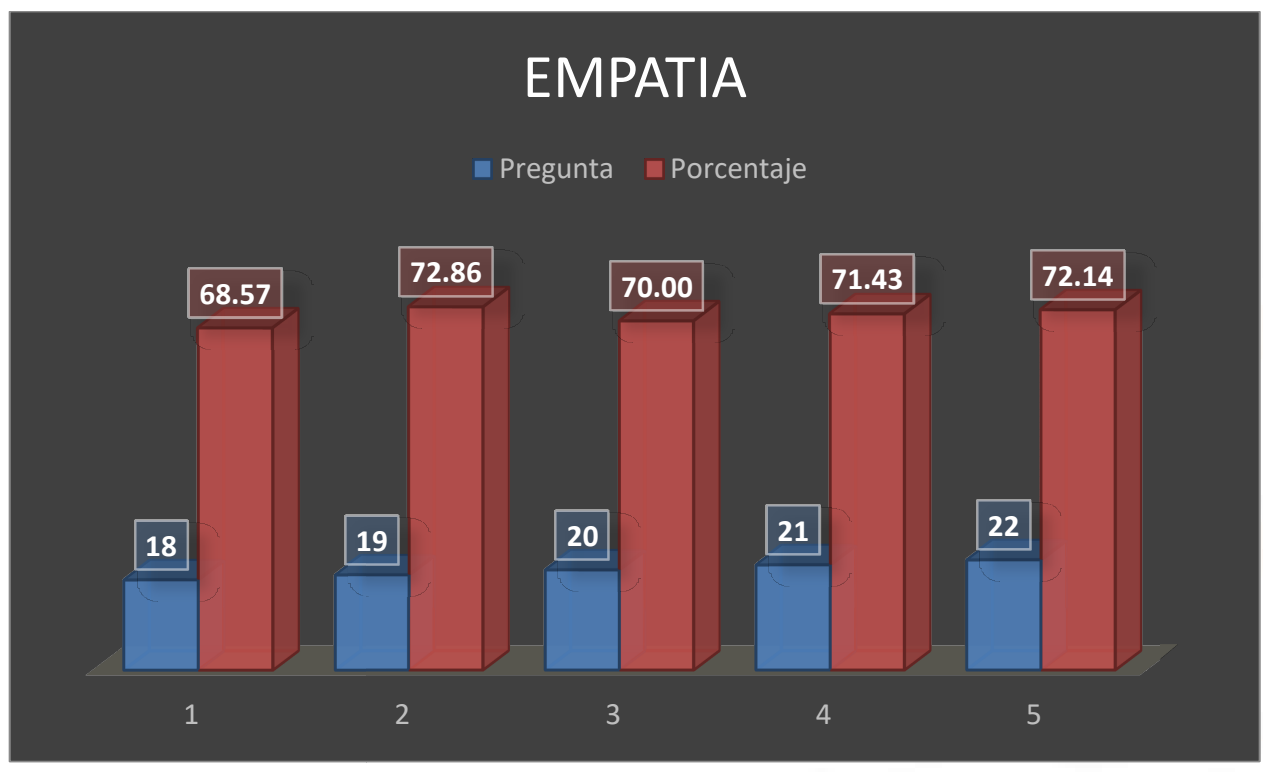

Figure 3: Examples of empathy elements results

The previous figure shows that all the results of the questions that make up the Reliability dimension have an average result of $70 \%$, which represents a regular result.

Figure 4 represents the results of the dimension: Response Capacity.

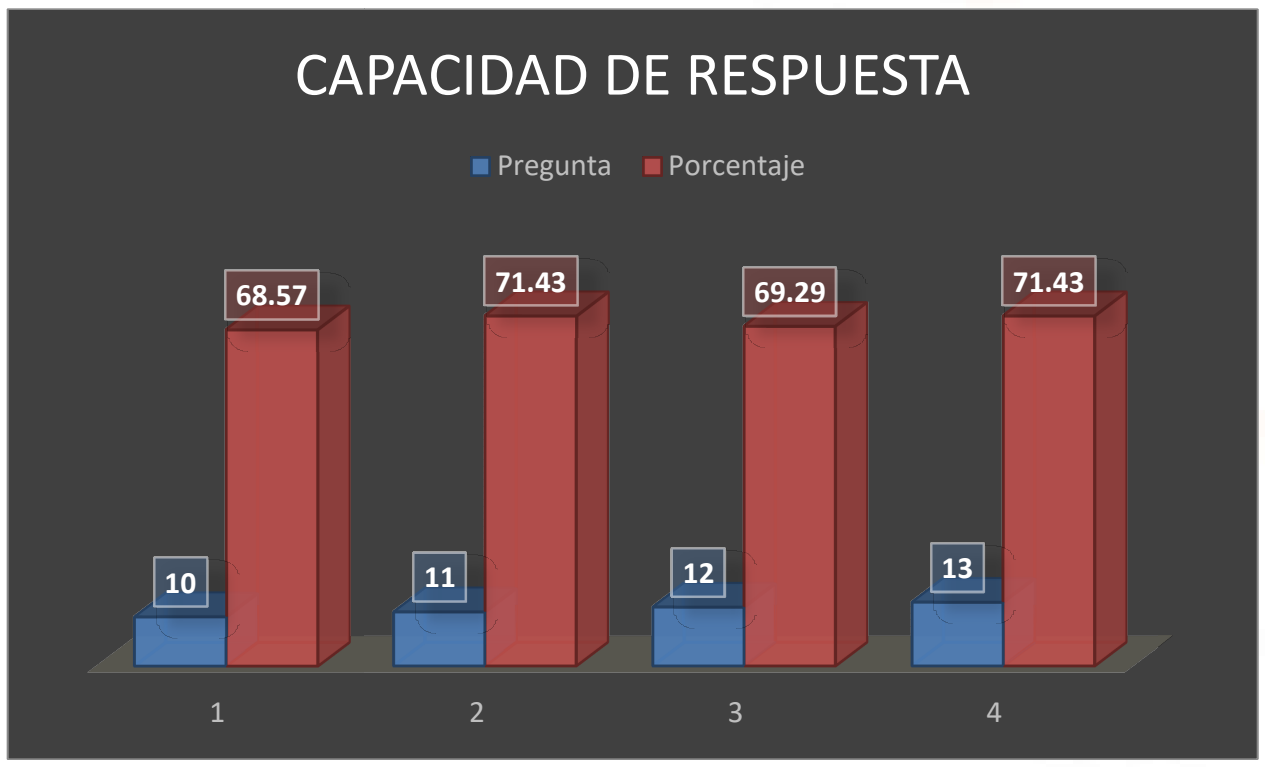

Figure 4: Example of results of responsiveness elements

The previous figure shows that all the results of the questions that make up the Reliability dimension have an average result of $70 \%$, which represents a regular result.

Figure 5 represents the results of the dimension: Security. 


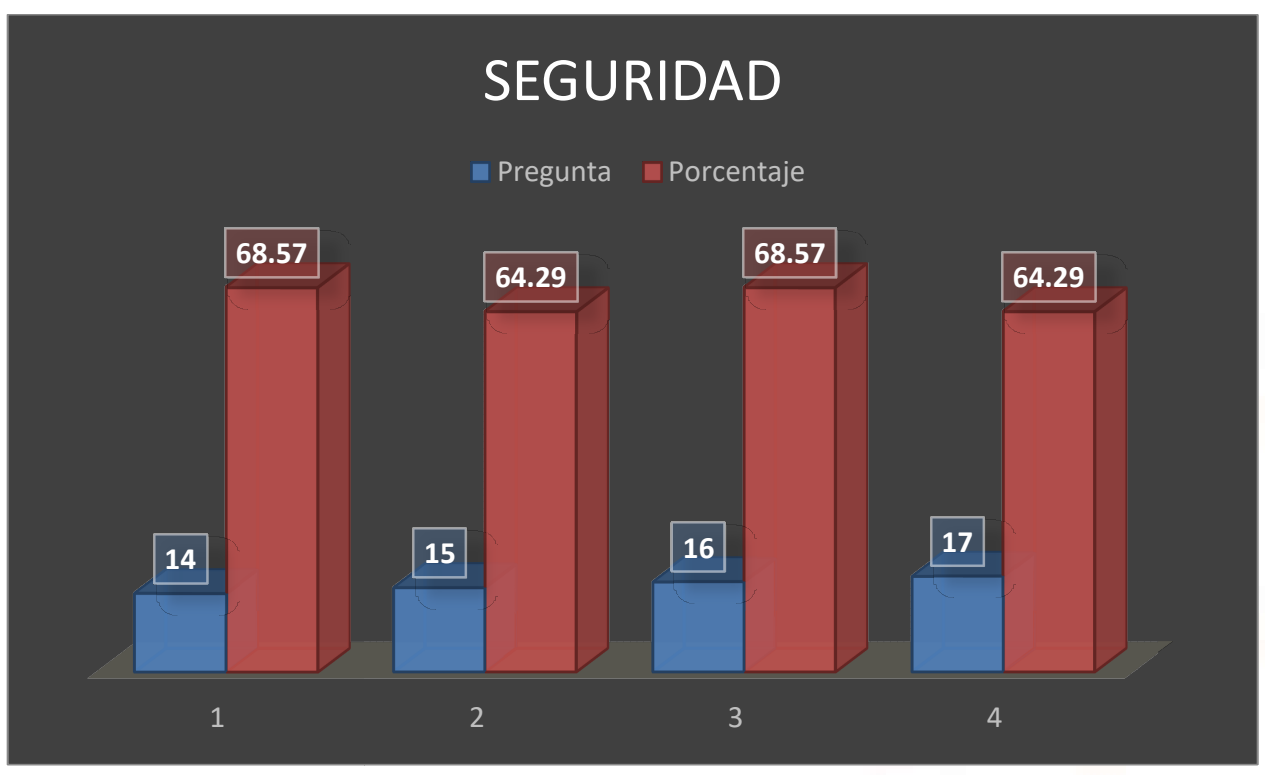

Figure 5: Example of security elements results

The previous figure shows that all the results of the questions that make up the Reliability dimension have an average result of $67 \%$, which represents a regular result.

Figure 6 represents the results of each dimension and the average of the five dimensions.

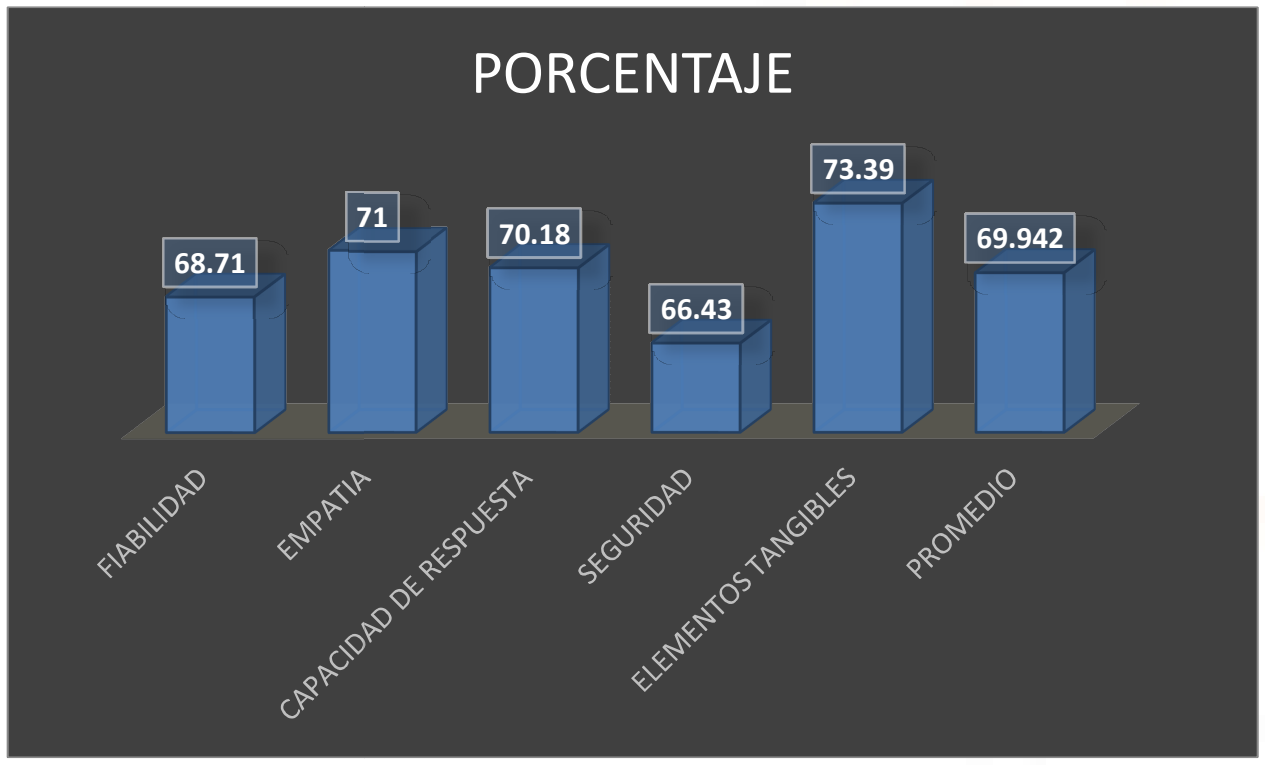

Figure 6: Example of results for each dimension

The figure above shows the results of each dimension and the average of the five dimensions. It can be observed that the average satisfaction of the students of the degree of Pedagogy is $69.942 \%$. This indicates that there are areas for improvement.

The first dimension that must be improved is the security dimension, which should establish courtesy strategies of the area of pedagogy and their ability to inspire confidence.
The second dimension that must be worked is the reliability dimension, which is to be careful in the ability of the service to perform as promised reliably and accurately.

\section{CONCLUSIONS}

Once the research was carried out, it was possible to obtain the evaluation of the customer service in the students of the pedagogy degree in the area of coordination in their night shift. 
Likewise, it was possible to identify the areas of opportunity that the area of pedagogical coordination has regarding the service of the students.

Finally, it was possible to propose alternatives of improvement for the service to the students in the area of coordination.

\section{ACKNOWLEDGMENT}

M.I.I. Arturo González Torres for his advice, mentoring and project management.

\section{BIBLIOGRAPHY}

1) Blanco Pineros, J. (2009). Medición de la satisfacción del cliente del restaurante museo taurino, y formulación de estrategias de servicio para la creación de valor. Carrera de Administración de Empresas Bogotá. Facultad de Ciencias Económicas y Administrativas. Pontificia Universidad Javeriana.

2) Botero, M. M. y Peña, P. (2006). Calidad de Servicio: El Cliente Incognito. Revista Suma Psicologica, Vol 13, №2.

3) Carman, J. M. (1990). Consumer perceptions of service quality: an assessment of the SERVQUAL dimensions. Journal of Retailing, Vol. 66 (Primavera), pp. 33-55.

4) Churchill, Gilbert A., Jr., Neil M. Ford, Orville C. Walker, Jr., 1979. "A Paradigm for Developing
Better Measures of Marketing Constructs", Journal of Marketing Research, 11 (August), 254 $-260$

5) Fisher, L. y Navarro, V. (1994). Introducción a la investigación de mercado. México: McGraw-Hill Interamericana S.A. de C.V.

6) Grönroos, C. (1982). An applied service marketing theory. European Journal of Marketing, $\mathrm{N}^{\mathrm{o}}$ 7, pp. 30-41.

7) Parasuraman, A., Zeithaml, V.A. y Berry, L.L. (1985). A Conceptual Model of Service Quality and Its Implications for Future Research. Journal of Marketing, vol. 49, pp. 41-50.

8) Parasuraman, A., Zeithaml, Valarie A., Berry, Leonard L. 1988. "SERVQUAL: A Multiple-Item Scale For Measuring Consumer Perceptions of Service Quality". Journal of Retailing, Vol. 64, $\mathrm{N}^{\circ} 1,12-40 \mathrm{p}$.

9) Pecina Rivas, M. I. (2014). Retos en la formación de profesionales logísticos: servicio y competitividad. Universidad Autónomadel Estado de México.

10) Zeithaml, V.A. (1988). Consumer perceptions of price, quality, and value: a means-end model and syntesis of evidence. Journal of Marketing, pp. 52, -22 . 